УДК 615.32

\title{
ИЗУЧЕНИЕ ХИМИЧЕСКОГО СОСТАВА ЖИРНОГО МАСЛА ИЗ СЕМЯН SILYBUM MARIANUM (L.) GAERTN.
}

\author{
() ШІ.А. Гасымова, Э.Н. Новрузов ${ }^{*}$, Н.П. Мехтиева \\ Институт Ботаники НАН Азербайджана, Бадамдарское шоссе, 40, Баку \\ AZ1073 (Республика Азербайджан), e-mail: sehla.qasimova.80@mail.ru
}

Silybum marianum (L.) Gaertn. - расторопша пятнистая (сем. Asteraceae Dumort.), распространена почти во всех ботанико-географических районах Азербайджана, произрастает от низменности до среднего горного пояса на сухих склонах, залежах, вдоль дорог и с краю посевов. Во многих районах Азербайджана имеет большие природные запасы. В данной статье приводятся физико-химические свойства, состав и содержание жирных кислот масла семян расторопши пятнистой. Семена были заготовлены в Шемахинском районе Азербайджанской Республики. Качественный состав и количественное определение метиловых эфиров жирных кислот определяли на хроматографе «НР» 6890 series c пламенно-ионизационным детектором. Для разделения использовалась 100-метровая капиллярная колонка «Agilent 11288А7». Температурный режим колонки запрограммирован следующим образом: начальная температура $140{ }^{\circ} \mathrm{C}-5$ мин стабильно, подъем температуры $4{ }^{\circ} \mathrm{C} /$ мин до $240{ }^{\circ} \mathrm{C}-15$ мин стабильно. Продолжительность анализа - 45 мин. Газноситель $\mathrm{H}_{2}$, ввод пробы - с делением потока. В результате исследования было установлено, что оно содержит 9 жирных кислот. Основную часть жирных кислот составляют линолевая $(46,1 \%)$ и олеиновая кислоты $(32,9 \%)$. Остальная часть жирных кислот приходится на долю пальмитиновой $(9,0 \%)$, стеариновой $(5,5 \%)$, линоленовой $(3,3 \%)$, эруковой $(2,1 \%)$, эйкозиновой $(0,8 \%)$ и миристиновой $(0,1 \%)$. В результате физического и химического анализов было установлено, что жирное масло, полученное из семян Silybum marianum, имеет следующие показатели: число омыления 199,4 , количество свободных жирных кислот - 2,5\%, пероксидное число - 3,9, йодное число - 116,7, весовая доля фосфорсодержащих веществ - 208,0 мг / кг, количество воска - 292 мг/кг.

Ключевые слова: Silybum marianum, семена, жирное масло, газожидкостная хроматография, жирные кислоты.

\section{Введение}

Silybum marianum (L.) Gaertn. - расторопша пятнистая (сем. Asteraceae Dumort.) это двулетнее стержнекорневое растение высотой 90-150 см. Распространена почти во всех ботанико-географических районах Азербайджана, произрастает от низменности до среднего горного пояса на сухих склонах, залежах, вдоль дорог и с краю посевов [1]. На посевных полях и пустырях р. пятнистая формирует чистые заросли в виде больших розовых пятен или образует полосы, вдоль дорог часто образует расторопшевую формацию. Во многих районах Азербайджана имеет большие природные запасы [2].

Целебные свойства р. пятнистой известны с древних времен. В народной медицине используется как само растение, так и полученный из него экстракт. Р. пятнистая обладает рядом защитных свойств против заболеваний печени. Используется при церрозе печени, алкогольном гепатите, вызываемом алкоголем, ожирении и отравлении печени. Компоненты, содержащиеся в этом растении оказывают непосредственное влияние на вирус гепатита С (HCV) [3].

Семена расторопши пятнистой содержат в составе 1,5-3\% суммы флавоноидов, из которых произ-

Гасымова Шахла Адалет - студентка,

e-mail: eldar_novruzov@yahoo.co.uk

Новрузов Эльдар Новруз - заместитель директора по научной работе, заведующий отделом растительных peсурсов, e-mail: eldar_novruzov@yahoo.co.uk Мехтиева Наиба Пирверди - ведущий научный сотрудник, e-mail: eldar_novruzov@yahoo.co.uk водится лекарственный препарат силимарин. В состав силимарина входит три основных компонента: флавоноиды силибин, силикристин и силидианин. Силимарин обладает антиоксидантным действием и стимулирует регенерацию печени при церрозе. Семена богаты жирными маслами (20-

\footnotetext{
* Автор, с которым следует вести переписку.
} 
$30 \%)$, белками (25-30\%), также содержат токоферол $(0,038 \%)$ и стеролы $(0,63 \%)$ включая холестерин, кампестерол, стигмастерин, ситостерин и другие [4].

Жирные масла являются незаменимым пищевым фактором [5], обеспечивающим человека необходимыми жирными кислотами (линолевая, линоленовая и арахиновая), не синтезирующимися в организме человека $[5,6]$. Они также используются в производстве лекарственных средств $[7,8]$. Значительный интерес представляет выявление новых источников жирных масел, содержащих высокое количество эссенциальных жирных кислот (С18:2; 18:3), относящихся к классу $\omega-2, \omega-3$ кислот.

Цель настоящей работы - установление жирно-кислотного состава и физико-химических показателей жирного масла из семян лекарственно-пищевого растения р. пятнистой, произрастающей в Азербайджане.

\section{Материалы и методы исследования}

Растительный материал для получения жирного масла был собран в окр. с. Гейлер Шамахинского района (Азербайджан) в июле 2015 г. в фазе полной спелости семян. Воздушно-сухие семена были высушены при температуре $105^{\circ} \mathrm{C}$ до остаточной влажности $2 \%$. Затем высушенные семена были измельчены и подвергнуты экстрагированию н-гексаном на аппарате Сокслета. Экстракт выпаривали с помощью эвапоратора. Качественный состав и количественное определение метиловых эфиров жирных кислот определяли на хроматографе «НР» 6890 series с пламенно-ионизационным детектором. Для разделения использовалась 100-метровая капиллярная колонка «Agilent 112-88A7». Температурный режим колонки запрограммирован следующим образом: начальная температура $140{ }^{\circ} \mathrm{C}-5$ мин стабильно, подъем температуры $4{ }^{\circ} \mathrm{C} /$ мин до $240{ }^{\circ} \mathrm{C}-15$ мин стабильно. Продолжительность анализа - 45 мин. Газ-носитель $\mathrm{H}_{2}$, ввод пробы - с делением потока.

Подготовка образца к анализу осуществлялась по ГОСТ Р 51486-99. В пробирке вместимостью 20 мл взвешивали навеску продукта массой 1 г и растворяли в 10 мл гептана. В полученный раствор пипеткой вносили 0,5 мл метанольного раствора гидроокиси калия, закрывали пробирку пробкой и интенсивно встряхивали в течение 2 мин. После пятиминутного отстаивания отбирали верхний слой для газохроматографического анализа.

Содержание компонентов вычисляли методом нормализации по площадям газохроматографических пиков без использования коэффициентов чувствительности.

Для идентификации метиловых эфиров жирных кислот использовали стандарт «Supelco 37 Component FAME Mix».

Физико-химические и органолептические показатели определяли по стандартным методикам (ГОСТ 18848-73; ГОСТ Р 50457-92; ГОСТ Р 51487-99; ГОСТ 18848-73; ГОСТ 5475-69; ГОСТ 5478-2014; ГОСТ Р 52676-2006; ГОСТ 5472-50).

\section{Результаты и обсуждение}

В результате применения в газожидкостных хроматографических исследованиях метиловых эфиров жирных кислот достигается большая эффективность разделения при более низкой температуре и меньшей продолжительности анализов. Результаты газожидкостных хроматографических анализов метиловых эфиров жирных кислот масел р. пятнистой показали, что полное разделение происходит в течение 30 мин. Спектр газо-жидкостной хроматографии метиловых эфиров жирных кислот исследованного масла (рис 1.) показал, что в нем находится миристиновая, пальмитиновая, стеариновая, олеиновая, линолевая, линоленовая, эйкозеновая и эруковая кислоты.

Как следует из спектра хроматограммы, количество отдельных жирных кислот в общей сумме неодинаково, содержание отдельных компонентов от общей суммы жирных кислот изменяется от 0,1 до $46,1 \%$ (рис 2).

Как видно на рисунке 2 , в составе жирных кислот (от общей суммы) преобладают линолевая $(46,1 \%)$ и олеиновая $(32,9 \%)$ кислоты. Остальная часть жирных кислот приходится на долю пальмитиновой $(9,0 \%)$, стеариновой $(5,6 \%)$, линоленовой $(3,4 \%)$ и эруковой $(2,1 \%)$ кислот. В общей сумме жирных кислот наименьшим количеством представлены эйкозеновая и миристиновая кислоты ( 0,8 и $0,1 \%$ соответственно). Полиненасыщенные жирные кислоты, которые очень полезны, содействуют снижению общего уровня холестерина. Ненасыщенные жирные кислоты в масле расторопши составляют почти более 70\% от общего количества жирных кислот. В связи с этим масло расторопши можно рекомендовать для сбалансирования уровня холестерина в организме. 


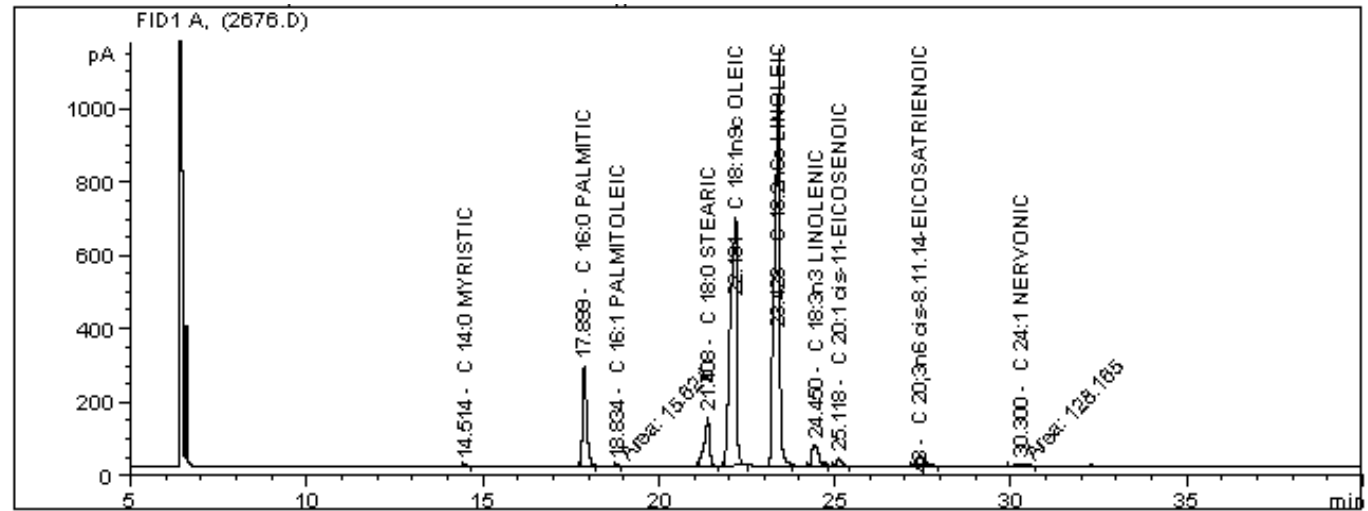

Рис. 1. Газожидкостная хроматограмма метиловых эфиров жирных кислот масла Silybum marianum

Рис. 2. Содержание жирных кислоты от общего, \%

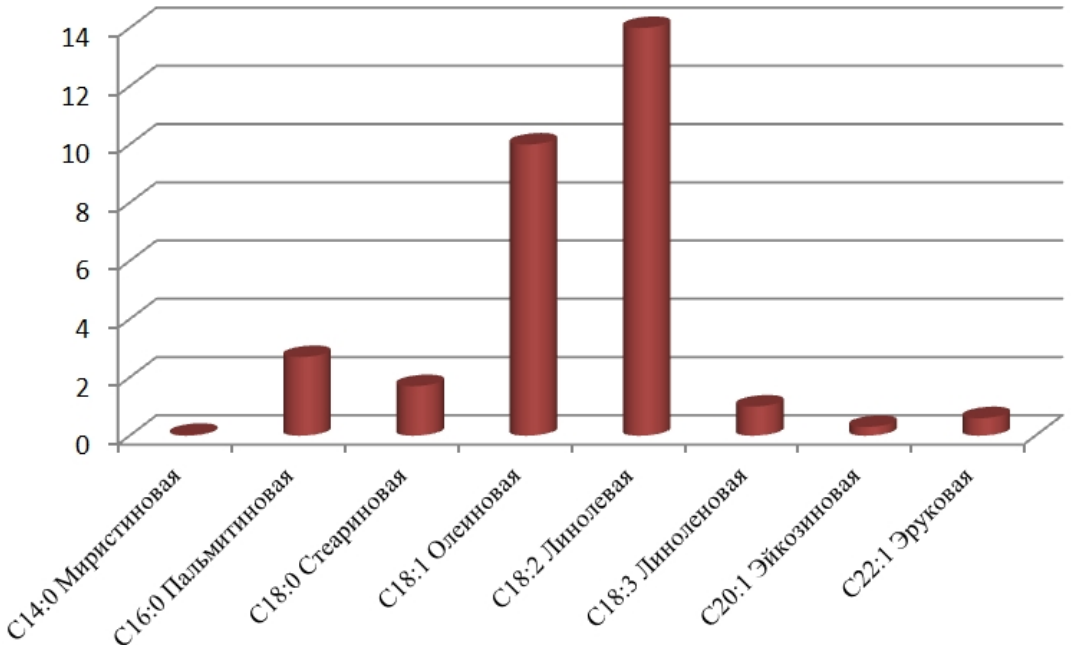

Высокое содержание линолевой кислоты, являющейся $\omega-2$ непредельной жирной кислотой, делает масло семян р. пятнистой ценным с диетической точки зрения. Известно, что масло, богатое линолевой кислотой, играет регулирующую роль при болезнях сердечно-сосудистой системы, атеросклерозе, гипертонии, способствует образованию ряда метаболитических регуляторов и структуры плазматической мембраны [9]. Линолевая кислота обладает также протекторными свойствами, является необходимым компонентом при синтезе керамидов, ключевой группой соединений, входящих в состав липидного барьера кожи, ингибируя УФ индуцированную гиперпигментацию [10]. Линолевая и линоленовая кислоты являются питательными веществами, необходимыми организму, которые не вырабатываются в нем естественным образом. Эти важные организму жирные кислоты должны быть приобретены через потреблямую пищу. Масло семян р. пятнистой очень ценно со значительным количеством эссенциальных жирных кислот (С18:2; 18:3), необходимых человеку. Эти кислоты относятся к классу $\omega-2$ и $\omega-3$ кислот, которые поступают в организм только с потреблением пищи [11]. Высокое содержание незаменимых жирных кислот в масле Silybum marianum делает ее пригодной для косметических и дерматологических композиций по причине ее антиоксидантного потенциала. Все это дает основание уверенно сказать, что масло р. пятнистой является ценным пищевым продуктом, медицинским и косметическим средством и может широко применяться для этих целей.

Для установления области применения растительного масла очень важно определение его физикохимической и органолептической характеристики. Эти данные очень ценны для стандартизации масла. Результаты анализов физико-химических и органолептических показателей масла представлены в таблице.

Результаты проведенного анализа показали, что жирное масло, полученное из семян $S$. marianum, имеет число омыления, равное 199,4. Этот показатель близок к таковому в подсолнечном масле [12], и в связи с этим масло, полученное из семян $S$. marianum, можно рекомендовать к использованию в пищевых целях.

Свободные жирные кислоты в масле образуются в результате гидролиза триглицеридов. Для $S$. marianum количество свободных жирных кислот составляет 2,5\%, пероксида - 3,9 ммоль $\mathrm{O}_{2} /$ кг, йодовое число - 116,7, весовая доля фосфорсодержащих веществ - 208,0 мг/кг и количество воска - 292 мг/кг. 
Физико-химическая и органолептическая характеристика жирного масла, полученного из семян Silybum marianum.

\begin{tabular}{|c|c|c|c|}
\hline Название эксперимента & Единица измерения & Метод испытания & Результат \\
\hline Органолептические показатели & & ГОСТ 18848-73 & $\begin{array}{c}\text { Прозрачная жидкость желтого } \\
\text { цвета, приятное на вкус }\end{array}$ \\
\hline $\begin{array}{l}\text { Свободные жирные кислоты (такие } \\
\text { как олеиновая кислота) }\end{array}$ & $\%$ & ГОСТ Р 50457-92 & 2,5 \\
\hline Перекисное число & ммоль $\mathrm{O}_{2} /$ кг & ГОСТ Р 51487-99 & 3,9 \\
\hline Цвет (Lovibond, 1 вкл) & Красный / желтый & ГОСТ 18848-73 & 4,1 красный, 30 желтый \\
\hline Йодное число & IV & ГОСТ 5475-69 & 116,7 \\
\hline Число омыления & $\mathrm{KOH}$ & ГОСТ 5478-2014 & 199,4 \\
\hline $\begin{array}{l}\text { Массовая доля фосфорсодержащих } \\
\text { веществ }\end{array}$ & мГ/кГ & ГОСТ Р 52676-2006 & 208,0 \\
\hline Содержание воска (мутность) & $\begin{array}{c}\mathrm{м} \Gamma / \mathrm{к \Gamma} \\
(\Delta \mathrm{NTU})\end{array}$ & ГОСТ 5472-50 & $292(22,7)$ \\
\hline
\end{tabular}

\section{Вblводы}

1. Изучение компонентного состава жирного масла расторопши пятнистой показало, что в нем содержатся миристиновая, пальмитиновая, стеариновая, олеиновая, линолевая, линоленовая, эйкозеновая и эруковая кислоты.

2. Жирно-кислотный состав и физико-химическая характеристка показывают, что ее можно использовать в лекарственных, косметических и пищевых целях.

\section{Список литературы}

1. Флора Азербаджана. Баку, 1961. Т. VIII. С. 419-420.

2. Мехтиева Н.П. Биоразнообразие лекарственных растений флоры Азербайджана: автореф. дис. ... докт. биол. наук. Баку, 2015. 44 с.

3. Giese LA. Milk thistle and the treatment of hepatitis // Gastroenterol Nurs. 2001. Vol. 24, no. 2. Pp. 95-97.

4. Milk Thistle and applications. URL: www.mdidea.com/products/herbextract/silymarin/data02.html. Accessed on 10/12.10.

5. Tooley P. The chemistry in industry, fats, oil and waxes. John Murrey Pub., London, UK. 1971. Pp. 16.

6. Triebold H.O., Aurand L.W. Food Composition and Analysis. D. Van Nostrand CO. Inc. Princeton, N. J, USA. 1963. $497 \mathrm{p}$.

7. Oliver C.A. Fatty Acid Composition of the oil extracted from Silybum marianum // Trop. Sci. Vol. 55. 1971. Pp. 19-55.

8. Ngoddy P.O., Ihekoronye A. Integrated food, science and technology for the tropics // Baileys Industrial Oil and Fat Product $3^{\text {rd }}$ ed. USA, Swern, 1967. 1103 p.

9. Viles R. O. Gottenbos J.J., RobblenG., Downey R.K. Nutritional characteristics and food uses of vegetable oils // Oil crops of the world. Mc. Graw Hill, New York, USA, 1989. 36 p.

10. Тютюнников Б.Н. Химия жиров. М., 1974. 260 с.

11. Григорьева В.Н., Лысицин А.Н. Факторы, определяющие биологическую ценность растительных жиров // Масложировая промышленность. 2002. №4. С. 14-17.

12. Shah H.U., Hussain T., Khan M.A. Gomal Uni // Pakistan Society of Agronomy Journal. 1984. N2. Pp. 133.

Поступило в редакиию 18 ноября 2016 г. 
Gasimova Sh.A., Novruzov E.N. ${ }^{*}$, Mehdiyeva N.P. THE STUDY OF CHEMICAL COMPOSITION OF FATTY OIL FROM THE SEEDS OF SILYBUM MARIANUM (L.) GAERTN.

Institute of Botany, National Academy of Sciences of Azerbaijan, Badamdar highway, 40, Baku, AZ1073 (Azerbaijan), e-mail: sehla.qasimova.80@mail.ru

Silybum marianum (L.) Gaertn. - Milk thistle (The family Asteraceae Dumort) distributed in almost all botanicalgeographical regions of Azerbaijan grows from lowlands to middle mountain zone on dry slopes, fallow lands, along roads and on the edge of crops. In many regions of Azerbaijan it has great natural resources. In this article resulting physical and chemical properties, composition and content of the seed oil fatty acids of milk thistle. Seeds were prepared in Shamakhi region of Azerbaijan Republic. Qualitative and quantitative determination of the composition of fatty acid methyl esters determined on chromatograph "HP" 6890 series with a flame ionization detector. 100 meter «Agilent 112-88A7» capillary column was used for separation. Temperature mode loudspeakers programmed as follows: initial temperature $140{ }^{\circ} \mathrm{C}-5$ min, stable temperature rise $4{ }^{\circ} \mathrm{C} / \mathrm{min}$ to $240{ }^{\circ} \mathrm{C}-15 \mathrm{~min}$ stably. Duration of analysis $45 \mathrm{~min} . \mathrm{H}_{2}$ carrier gas, injection - split. The study established that it comprises 9 fatty acids. The main part of fatty acids comprise linoleic $(46,1 \%)$ and oleic acid $(32,9 \%)$. The remainder of the fatty acids accounted for palmitic $(9,0 \%)$, stearic $(5,5 \%)$, linolenic $(3,3 \%)$, linolenic $(2,1 \%)$, eykozinovoy $(0,8 \%)$ and myristic $(0,1 \%)$. As a result of the physical and chemical analyzes, it was found that a fatty oil obtained from the seeds of Silybum marianum has the following characteristics: 199,4 saponification value, the amount of free fatty acids, $2,5 \%$, peroxide value 3,9 , iodine value of 116,7 , a weight the proportion of phosphorous $208,0 \mathrm{mg} / \mathrm{kg}$, the amount of wax in the $292 \mathrm{mg} / \mathrm{kg}$.

Keywords: Silybum marianum, seeds, fatty oil, gas-liquid chromatography, fatty acids.

\section{References}

1. Flora Azerbadzhana. [Флора Азербайджана]. Baku, 1961, vol. VIII, pp. 419-420. (in Russ.).

2. Mekhtieva N.P. Bioraznoobrazie lekarstvennykh rastenii flory Azerbaidzhana : avtoref. dis. ... dokt. biol. nauk. [Biodiversity of medicinal plants of flora of Azerbaijan: the author's abstract of the dissertation of the doctor of biological sciences]. Baku, 2015, 44 p. (in Russ.).

3. Giese LA. Gastroenterol Nurs., 2001, vol. 24, no. 2. pp. 95-97.

4. Milk Thistle and applications. URL: www.mdidea.com/products/herbextract/silymarin/data02.html. Accessed on 10/12.10.

5. Tooley P. The chemistry in industry, fats, oil and waxes. John Murrey Pub., London, UK. 1971. Pp. 16.

6. Triebold H.O., Aurand L.W. Food Composition and Analysis. D. Van Nostrand CO. Inc. Princeton, N. J, USA. 1963. $497 \mathrm{p}$.

7. Oliver C.A. Trop. Sci., 1971, vol. 55, pp. 19-55.

8. Ngoddy P.O., Thekoronye A. Baileys Industrial Oil and Fat Product. $3^{\text {rd }}$ ed. USA, Swern, 1967. 1103 p.

9. Viles R. O. Gottenbos J.J., Robblen G., Downey R.K. Oil crops of the world. Mc. Graw Hill, New York, USA, 1989. $36 \mathrm{p}$.

10. Tiutiunnikov B.N. Khimiia zhirov [Chemistry of Fat]. Moscow, 1974, 260 p. (in Russ.).

11. Grigor'eva V.N., Lysitsin A.N. Maslozhirovoi promyshlennost', 2002, no. 4, pp. 14-17. (in Russ.).

12. Shah H.U., Hussain T., Khan M.A. Pakistan Society of Agronomy Journal, 1984, no. 2, pp. 133.

Received November 18, 2016

Revised March 9, 2017

\footnotetext{
* Corresponding author.
} 
